\title{
Maximizing Appropriate Technology to Advance Development in Indonesian Economic Through Industrial Revolution 4.0
}

\author{
A Febriansyah ${ }^{1 *}$, F Hartanto $^{2}$ \\ \{ $\underline{\text { angky@email.unikom.ac.id }}{ }^{1}$, fahartanto@email.unikom.ac.id ${ }^{2}$ \} \\ Departemen Akuntansi, Universitas Komputer Indonesia, Indonesia ${ }^{1}$ \\ Departemen Akuntansi, Universitas Komputer Indonesia, Indonesia ${ }^{2}$
}

\begin{abstract}
This research aims to optimize local resources to suit their needs and abilities, also be able to compete with developing and developed countries, so that they can produce useful technology in terms of quality and quantity that could change the mindset of the Indonesian people. This research method used a literature study that discussed how the weakness of technological development in Indonesia is still incompatible with the current state of the government. Because it still does not reflect the country's resources and needs, also analyzes several variables that make weaknesses in technology improvement that have not succeeded in making technology a competitive and superior sector. As a results, this study will propose appropriate technology and support the improvement of Indonesian economy based on local resources according to the capabilities and technological needs in Indonesia, so that it can compete with other countries in Industrial Revolution 4.0.
\end{abstract}

Keywords: Revolution 4.0, technological development

\section{Introduction}

From some empirical researches, it can be proven that the development or maximizing of appropriate technology greatly contributes significantly and competently to industrialization that builds the economy in a more developed country [1]. Some researchers coincident that maximizing appropriate technology at the micro and macro level can contribute to the economic development of a country so that the country can contend competently with other countries [2]. In the current era of globalization, it can be predicted that technological progress will provide a huge contribution of more than 75 percent in world economic development including Indonesia which is still a developing country. In the reform era of the Third President of Indonesia, namely B.J. Habibie, where there are a lot of movers and technology developers across Indonesia sprung up because at that time Indonesia needed experts in their sector so that advances in technology were very significant [3]. 
As a result of the achievement of the Third President of Indonesia at that time was $\mathrm{CN}-235$ aircraft through the cooperation of PT. DI and CASA. However, PT. DI does not have sufficient funds to finance the flight-worthy certification, which finally PT. DI has not been able to market its products until now.

A business that is successful in winning the competition is determined by the technology that is created possesses superior and competitive value in order to maximize appropriate technology to build the economy. Maximizing this technology requires every transformation process from many inputs to produce output that can provide added value at each stage of the process for generating the right technology on facilitating the mindset to become more advanced so that the economy increases significantly [4]. In the development of technology, at this time, every country and business will be constantly facing two choices. First, technology in its development through a new process of discovery and innovation. Second, developing technology can go through the process of transferring appropriate technology. There are almost no country and business that can satisfy all types of technology needed by every country's needs [5]. In overcoming this situation, a country or business can implement a technology strategy that will be said several created and several buying strategies. Technology several crated can be done developers through research and development, while several buying technology can be done in the process of transferring appropriate technology [6]. Therefore in developing technology is needed to encourage economic development of a country or business, as well to create a superior in order to compete competitively for a country or business. Because of it, every country or business is required to always participate in developing appropriate technologies on an ongoing basis which is an unavoidable need in the current era of globalization [7]. In addition, a country or business can also be demanded in determining a choice pragmatically related to the level and type of technology that can be developed in a country or business to meet the criteria of appropriate technology [8]. This far, Indonesian government has tended to implement experimental technology in the development of the required technology. As a result, the technology that is developed has more error than succeeded, so the technology has not yet fulfilled the criteria of appropriate technology [9]. The government's choice to reform on developing high technology in the aircraft industry that established PT Dirgantara (PT DI) from IPTN, and in the automotive industry with projects often called "MobNas", are examples that do not include appropriate technology, so it must be developed in Indonesia.

The purpose of this study is to optimize local resources to suit their needs and abilities and be able to compete with developing and developed countries so that they can produce technology that is useful in terms of quality and quantity that makes the mindset of the Indonesian people continue to grow and even progress and experience changes in the times and the future. The method was taken through literature study and references from previous research to renewable in terms of quality and quantity to produce renewable research and provide advice to the government so that Indonesia becomes an advanced country and can compete with major countries around the world [10]. 


\section{Method}

This study used kinds of a literature study to find the variables related to the industrial revolution 4.0 which affecting the economy by using appropriate technology as well as using and developing previous research related to the development of appropriate technology. So it could analyze and identify how much the influence of appropriate technology in the industrial revolution 4.0 that the Indonesian economy could be able to contend competitively with other developing countries or developed countries that exist throughout the world.

\section{Results and Discussion}

The Indonesian nation inevitably, likes and dislikes, must be prepared to face global competition that cannot be covered or avoided because it has been running as the times progress. According to Bob Gordon of Northwestern University, as quoted Paul Krugman, it has been noted that before the industrial revolution 4.0 there had been three industrial revolutions that led to changes in all countries in the world. First, found trains and steam engines around 1750 1830. Second, the discovery of communication, electricity, oil and chemical equipment around 1870 - 1900. Third, the invention of computers, the internet and mobile phones around 1960 until now. In another statement stated that the third industrial revolution began around 1969, which began with the emergence of information technology and automation machines that made it easier for people to move. As with the three previous industrial revolutions, the presence of industry 4.0 can be believed to increase the level of productivity competently. According to a survey Mckinsey of 300 prominent corporate leaders in Southeast Asia in particular and resulted in 9 out of 10 respondents believing that the effectiveness of the industrial revolution 4.0 had almost nothing to doubt when viewed from these results. However, when asked if they were ready to march, only 48 percent stated their readiness, so industry 4.0 still left a question mark about its future. Industrial revolution 4.0 is the latest technology trend that has been designed in such a sophisticated way that influences the production process in the manufacturing sector. These advanced technologies include artificial intelligence (AI), big data, e-commerce, fintech, shared economies, to the use of robots. It was written by Krugman "A New Industrial Revolution: The Rise of the Robots", The New York Times, 17/1/13, that the use of smart technology can indeed increase Gross Domestic Product (GDP). However, this has the effect of reducing the demand for labor, including the smart ones. But it will not happen immediately because there are stages in each process [7].

One thing that can not be avoided, namely the industrial revolution 4.0 has come and it is impossible to reject or avoid it. Jeffrey Sachs Center, that more than half of ASEAN's population totalling 630 million people are under 30 years old, where 90 per cent of those aged 15-24 are familiar with the internet and the digital world which is a big capital going forward that can create additional output USD 1 trillion, so that GDP can reach USD 5,25 trillion in 2025. The International Labor Organization (ILO) in ASEAN countries will move 57 per cent to automation in the coming decades. Indonesia focuses on five leading manufacturing sectors: (1) food and beverages, (2) textiles and clothing, (3) automotive, (4) chemistry, and (5) electronics 
because five manufacturing sectors can contribute greatly to GDP and possess power competitive international competition [10]. These five sectors can be considered as contributors to more job creation and new investments that are quite attractive because they are technologybased. In realizing industrial revolution 4.0 in order to implement appropriate technology so that the Indonesian economy is more advanced in 2030 because the 5 sectors become Indonesia's main commodities that can contribute and compete towards the top 10 supporting the world economy. Therefore the Indonesian government designed a road map called Making Indonesia 4.0 which contained a number of initiatives that were implemented to support the employment and economy of the Indonesian nation. The implementation of the fourth generation industry must, of course, be followed by the incorporation of a sustainable and healthy ecosystem. It is effective and efficient and it can move all economic sectors, especially 5 main commodities that can compete and be competent in their fields so that past mistakes will not be repeated in terms of economics and technology. (Figure 1).

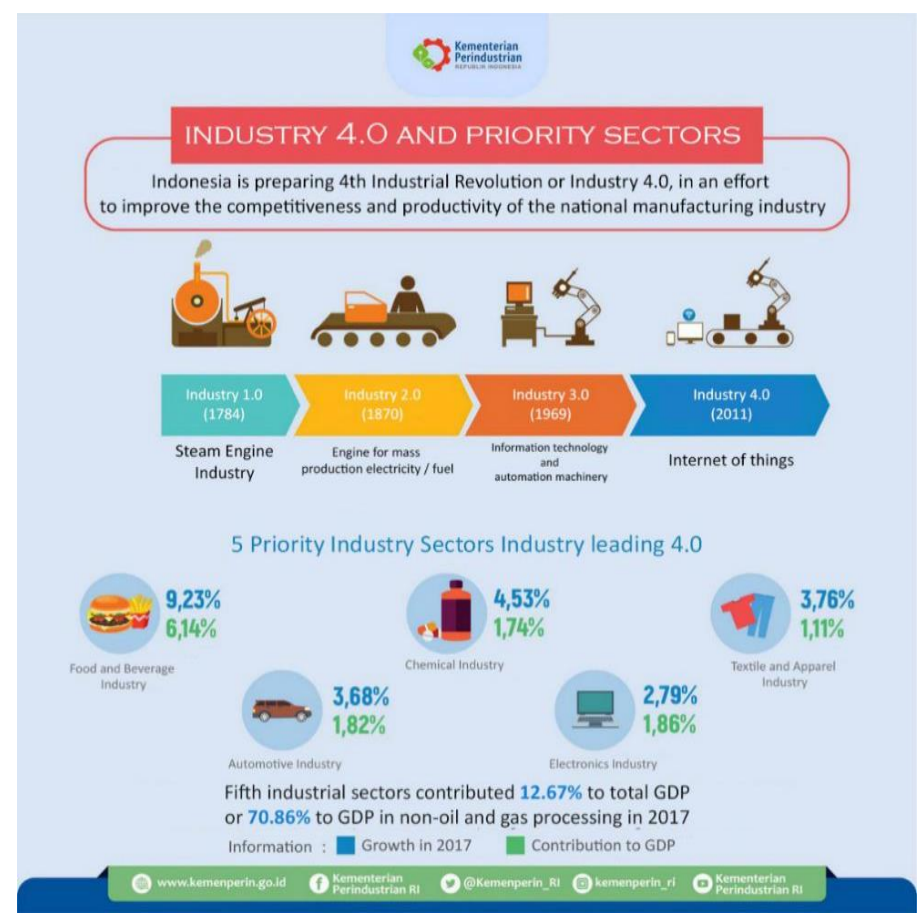

Fig. 1. 5 Main Commodity

According to Richard Mengko [9], to achieve a successful business in the digital era currently, ecosystems and communication are needed to be formed consistently for business people to achieve mutually beneficial and strong ecosystems. But the Indonesian people still have not used it effectively and efficiently in matters of productivity that can develop the digital economy in Indonesia. Actually the industrial revolution 4.0 has been running at this time in Indonesia, especially in big cities, it is very helpful because of the busyness. Industrial 
revolution 4.0 is a near future not change in 50 years, but only a matter of months. Do not let us fall behind that keyword. Second, building the current ecosystem with Go-Jek has changed habits to our mindset. The natural ecosystem can be described as a tree. The tree will be fertile if watered or exposed to rain regularly and given fertilizer. Likewise, the industry will not be said to be fertile if a controlled ecosystem is not gradually created according to technological progress so that the Indonesian economy will increase (Figure 2).

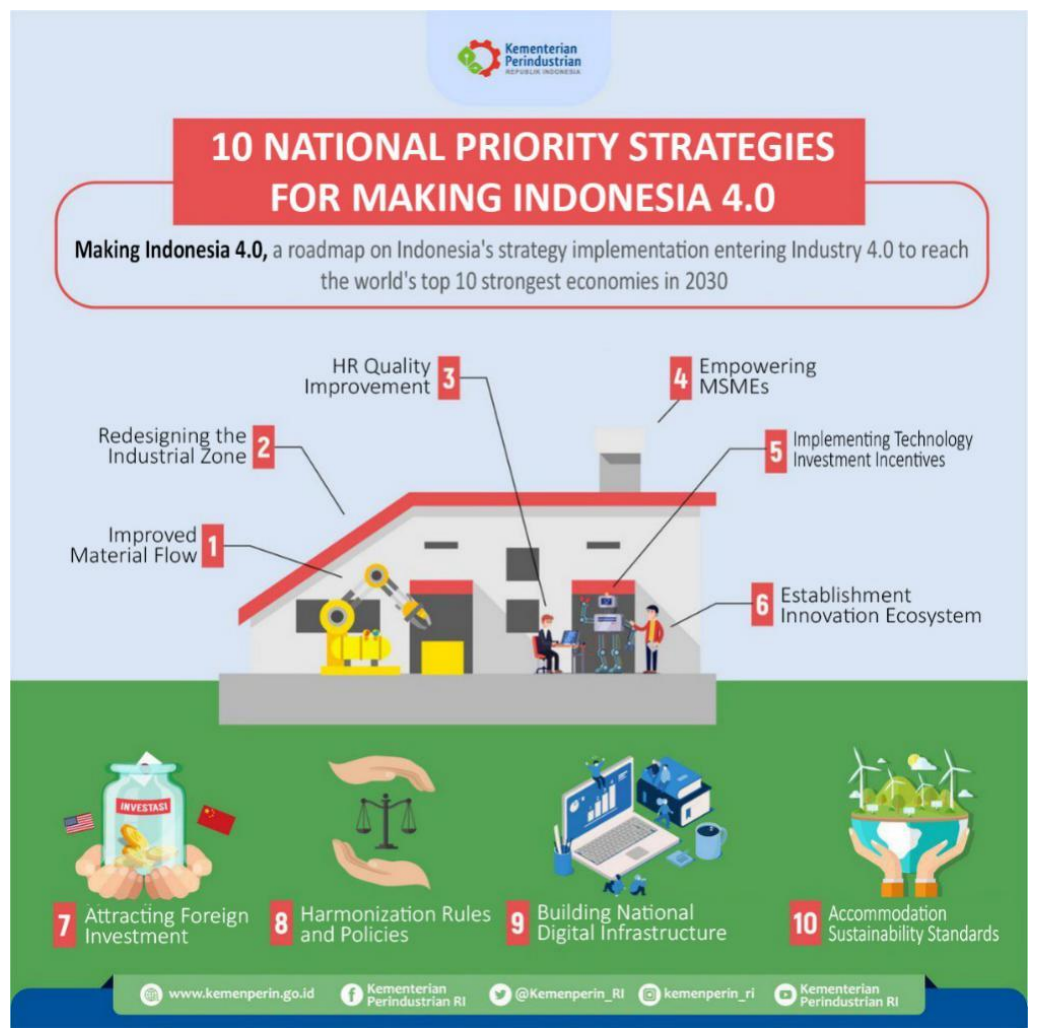

Fig.2. Industrial Revolution 4.0 in Indonesia

In the face of the industrial revolution first, every country or business entity must understand the market and mapping characteristics of the "underserved market", the market that is still not well served using of technology. Researchers from RISE Research added that Indonesia had become one of the targets for every industry player in the world who is fighting to enter the Indonesian market. Therefore, there must be safeguards that can protect and maintain balance and sustainability in various sectors. In Indonesia, there are still many potentials that have not been extracted, while limited services and the utilization of existing services have not been maximized. To maintain the balance of economic growth and the faster technological progress and character of the market that changes significantly. Therefore, collaboration in the Digital Era with economic growth is needed. The point is that change that changes our mindset and the industrial revolution inevitably has to be faced now in responding 
to it and making the challenge an opportunity or thinking Out of the Box maximally to be stronger amidst the onslaught of foreign expansion [10].

New approaches and abilities are needed to build innovative and sustainable production systems. This was stated by Minister of Industry (Menperin,) Airlangga Hartanto on the sidelines of the World Economic Forum on ASEAN 2017 in Phnom Penh, Cambodia "When countries enter Industry 4.0 comprehensive and sustainable industrial growth tends to occur. Therefore, we have prepared four strategic steps so that Indonesia implements Industry 4.0". In government responses that are pushing the Indonesian labor force to continue to learn and improve skills to understand using the Internet of Things technology or integrate internet capabilities with the industrial production sector. The development system at the same time preparing skilled workers who are ready to use in the industrial world with a target of one million people by 2019. The second step using digital technology to boost productivity and competitiveness for small and medium industries (IKM) so that they can penetrate the export market through e -smart IKM [3].

Indonesia is famous for its abundance of Natural Resources (SDA) such as forests, are still said to be extremely abundant. However, Indonesia's forests are currently exploited legally and illegally, and burned almost every year, of course in time they will become extinct too. In addition to an abundance of natural resources, Indonesia awarded climatic and natural conditions that enable the developing-and-growth of various species of flora and fauna. In conditions of globalization increasingly fierce competition, the creation of competitive advantage for an industry can only be done with appropriate technology development efforts or at least give a touch of technology in every development and economic growth for the industry independently.

One of the industries that have the appropriate technology in the face of the industrial revolution 4.0 is a creative industry because it has advantages. There are two things that can't be replaced by machines, namely creativity and something related to taste.

In addition, Indonesia can develop what is not developed by other countries, namely agroindustry because the existing climate and natural conditions are very possible in optimal economic utilization in Industrial Revolution 4.0. Because at the development phase agroindustry uses a touch of technology (Technology Touch) that is not too expensive and not so complicated compared to technology development in the manufacturing industry. Agroindustry development that tends to be labor-intensive will face Industrial Revolution 4.0 and involves many parties such as farmers and small businesses (MSMEs). This agro-industry development must be sustainable or relate to the development of processing industries to increase the added value commodities that can be produced and utilize appropriate technology to support the Indonesian economy. For example, building an oil palm processing industry along with its derivative commodities. In addition, the development of agroindustry and its processing industry must be export-oriented to the global market, thus demanding quality assurance required by the global market [5]. 
Leading to characteristics of appropriate technology-related a technology needed on target so that it can help human work effectively and efficiently make the economy significantly increase through a process that has measurable and controlled stages. Agro-industrial development along based processing technology is an appropriate technology for the nation of Indonesia. Besides that, the emergence of startups such as Go-Jek, Go-Food, Go-Car, Tokopedia, Bukalapak, and so on makes Indonesia able to compete in economic development independently and will provide an influential contribution in overcoming the problem of unemployment and poverty with facing the industrial revolution 4.0 [10].

Economics predicts that in addition to the agro-industrial world that can affect the economy but there is still a very influential sector creative industry. Global community dependence on information technology in daily activities has led to the exponential growth creative industries that include such films, music, music publishing, entertainment and fashion that has grown in three years (Figure 3).
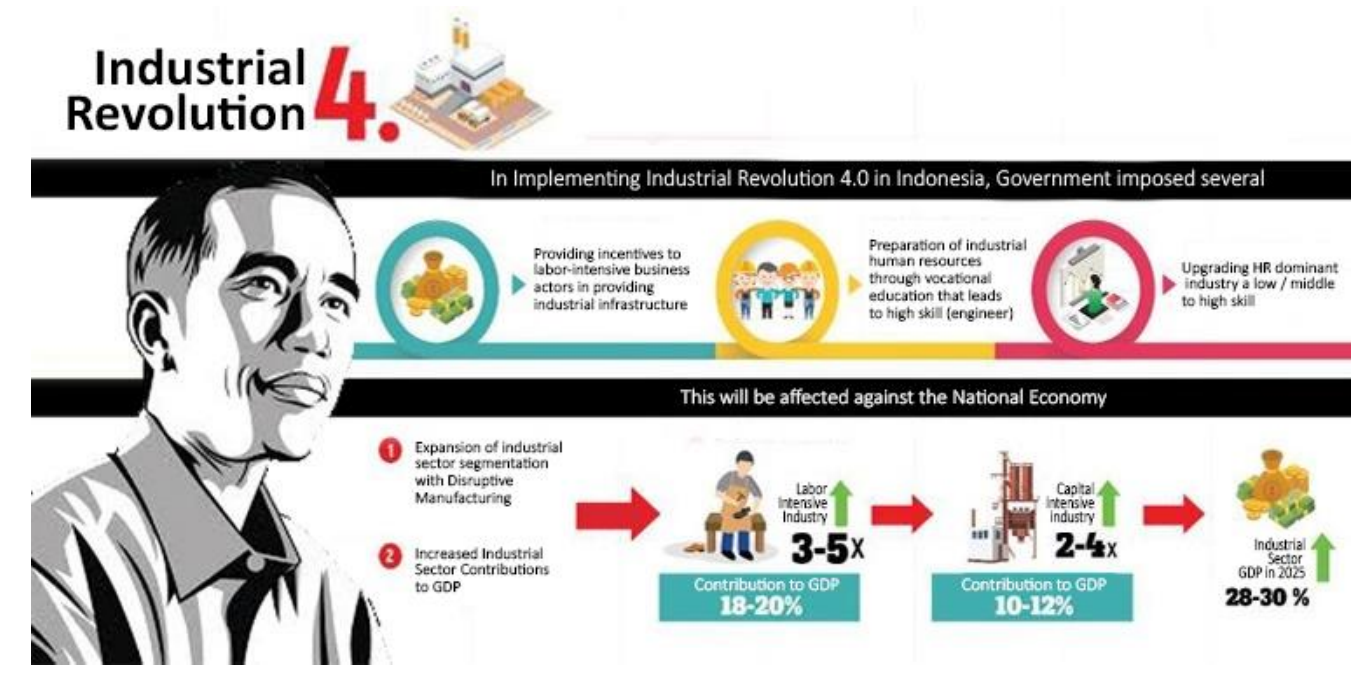

Fig. 3. Government Plan to appearance the Industrial Revolution 4.0

Based on national data, the creative industry sector has absorbed 15,9 million workers with a contribution of 7,3 percent of gross domestic product (GDP) or equivalent to Rp. 852 trillion. On a global scale the economic value of the creative industry even goes beyond the oil industry. Based on data released by the United Nations Conference on Trade and Development (UNCTAD) in 2012, the creative industry contributed USD 2,2 trillion or 230 percent more than the value of OPEC oil exports which made a creative industry the most innovative economic sector. Because Indonesia has a very rich culture and Indonesian tradition can still be explored to be developed so that it is still widely open will be worked on businesses in Indonesia by using appropriate technology that will maximize Indonesia's economic growth to be able to compete with other countries [4]. 


\section{Conclusion}

From time to time, a very sustainable technology and economy cannot be separated, because they have processes along a significant stage mainly in the industrial revolution 4.0. Industries that have appropriate technology cannot be affected and are able to face the 4.0 industrial revolution, namely agro-industry and creative industries as they involve many parties. So, many jobs will be open to employers and job seekers. In both sectors have business potential because of the wealth of natural resources (SDA), Indonesian culture and traditions that can still be explored for the developed with high creativity that produces the most innovative and superior commodities to maximize appropriate technology to build the Indonesian economy forward on industrial revolution 4.0.

\section{References}

[1] Baruah D.: Toward Strategic Economic Cooperation Between India and Japan. Carnegie India. 7, 272-94. (2016).

[2] Francis, R. J., J. Rose, and Z. Vranesic. Chortlecrf: Fast Technology Mapping for Lookup TableBased FPGAs. Proceedings 28th ACM/IEEE Design Automation Conference. 5, pp. 513-19. (1991). [3] Dedrick, J., Kraemer K.L., Linden G.: Who Profits from Innovation in Global Value Chains: A Study of the iPod and Botebook PCs. Industrial and Corporate Change, 19(1), pp. 111-16. (2010).

[4] Los D., Timmer M., De Vries G.: Global Value Chains: 'Factory World' is Emerging. The Age of Global Value Chains: Maps and Policy Issues. Edited by J. Amador, F.Di Mauro. London: CEPR Press, 14, pp. 36-47. (2016).

[5] Yang C.: Relocating Labour-Intensive Manufacturing Firms from China to Southeast Asia: A Preliminary Investigation. Bandung: Journal of the Global South, 4(3), 118-45. (2016).

[6] Mashukova, B.S.: Basic principles of the cyclical economy (economy of a closed cycle), European Science, 17(7) p. 14-6. (2016).

[7] Ellen MacArthur Foundation and WRAP. Favourable System Conditions and Economic Opportunities. Wales and the Circular Economy. Cowes. 11, 365-77. (2014).

[8] Ellen MacArthur Foundation.: Economic and business rationale for an accelerated transition. Towards the Circular Economy. Cowes. 9, 244-76. (2013).

[9] Coldwell, D, F Herbst.: Business Research. Cape Town: Juta and Co Ltd. 8, 443-76. (2012).

[10] Soegoto, Drs. IR. Eddy Soeryanto. : Entrepreneurship Menjadi Pebisnis Ulung (Edisi Revisi). Jakarta: PT Elex Media Computindo. 2, 342-65. (2015). 